\title{
O dever de fundamentação analítica no Processo Civil e as pontes com a teoria da
}

\section{argumentação jurídica}

The duty of analytical reasoning in Civil Procedure and the bridges with the theory of legal argumentation

El deber del razonamiento analítico en el Procedimiento Civil y los puentes con la teoría de la argumentación jurídica

\section{Resumo}

O presente trabalho é pautado na necessidade de investigação da importância das teorias da argumentação jurídica para a aplicação do dever de fundamentação analítica formado pelas normas regentes do Código de Processo Civil, dogmatizadas pela preocupação de se garantir racionalidade às decisões judiciais. Sendo assim, partindo de estudos e investigação bibliográfica, desenvolve a construção de discussão que abrange o conceito da sentença em nosso paradigma contemporâneo no Estado Democrático de Direito, preocupado com a tutela efetiva de direitos materiais, delimitando o papel de legitimação do Poder Judiciário. Ainda, aborda a formação de um dever de fundamentação analítica, com esteio no dever de colaboração, como metacritério de validade das razões justificativas da decisão judicial. Ao final, conclui pela importância das teorias da argumentação, situando que a identificação do contexto de justificação, delineado por seus estudiosos, têm contribuído para a dogmática, atendendo aos anseios de racionalidade dos argumentos e, em decorrência, critérios de controle e segurança jurídica.

Palavras-chave: Teoria do direito; Processo civil; Teoria da decisão judicial; Dever de fundamentação analítica; Teorias da argumentação jurídica.

\begin{abstract}
The present work is guided by the need to investigate the importance of theories of legal argumentation for the application of the duty of analytical reasoning formed by the governing norms of the Code of Civil Procedure, dogmatized by the concern to guarantee rationality to judicial decisions. Thus, starting from studies and bibliographical research, it finds the construction of a discussion that encompasses the concept of sentence in our contemporary paradigm of guardianship of rights, in the Democratic State, delimiting the legitimizing role of the Judiciary. Still, it addresses the formation of a duty of analytical reasoning, based on the duty of collaboration, as a meta-criterion of validity of the reasons justifying the court decision. In the end, it concludes for the importance of theories of argumentation, stating that the identification of the context of justification, outlined by its scholars, has contributed to dogmatics, meeting the concerns of rationality in arguments and, as a result, criteria of control and legal certainty.
\end{abstract}

Keywords: Theory of law; Civil procedure; Judicial decision theory; Duty of analytical rationale; Theories of legal argumentation.

\section{Resumen}

El presente trabajo se guía por la necesidad de investigar la importancia de las teorías de la argumentación jurídica para la aplicación del deber de razonamiento analítico conformado por las normas rectores del Código de Procedimiento Civil, dogmatizado por la preocupación por garantizar la racionalidad a las decisiones judiciales. Así, a partir de estudios e investigaciones bibliográficas, se encuentra la construcción de una discusión que engloba el concepto de sentencia en nuestro paradigma contemporáneo de tutela de derechos, en el Estado Democrático, delimitando el rol legitimador del Poder Judicial. Aún así, aborda la formación de un deber de razonamiento analítico, basado en el deber de colaboración, como metacriterio de validez de las razones que justifican la decisión judicial. Al final, concluye por la importancia de las teorías de la argumentación, afirmando que la identificación del 
contexto de la justificación, esbozada por sus estudiosos, ha contribuido a la dogmática, atendiendo las preocupaciones de racionalidad en los argumentos y, como resultado, criterios de control. y seguridad jurídica.

Palabras clave: Teoría del Derecho; Proceso civil; Teoría de la decisión judicial; Deber de justificación analítica; Teorías de la argumentación jurídica.

\section{Introdução}

A compreensão do conceito de sentença passa pela perspectiva da necessidade de efetiva concretização dos direitos. O processo é um caminho para lograr-se a solução da demanda, mas, de maneira precípua, garantir a entrega do bem da vida perseguido. Por isso, o ato decisório está atrelado à tutela visada.

A sentença, logo, abandonou a visão do Código Buzaid (Código de Processo Civil de 1973), em que era concebida apenas como o ato processual que extinguia o processo e se sujeitava ao recurso de apelação, diferenciando-se dos demais atos decisórios impugnáveis, de regra, pela via do agravo (Marinoni et al., p. 335).

Esclarece Oliveira (2003, p. 21) que as ideias do instrumentalismo ou formalismo puro teve sua importância, contudo passou por mudanças por conta do desenvolvimento cultural:

Revela-se indubitável o valor positivo das ideais defendidas pelo instrumentalismo. Trata-se de movimento de profundo impacto na doutrina brasileira. Todavia, o desenvolvimento cultural do processo brasileiro e os influxos de outros campos do Direito permitem algumas ponderações a respeito de determinadas ideias assumidas por essa corrente de pensamento. Em primeiro lugar, mostra-se inadequado outorgar função puramente declaratória à jurisdição, pois acaba por apoucar o papel do juiz e das partes ao longo do processo. Na realidade, a jurisdição, longe de apenas declarar o direito, opera verdadeira reconstrução da ordem jurídica mediante o processo, tendo por matéria-prima as afirmações de seus participantes a respeito da situação litigiosa.

$\mathrm{Na}$ atual roupagem, a sentença é tida como o ato do Juiz que, preocupado com a função de tutela dos direitos, resolve ou não o mérito da causa, ou seja, soluciona a demanda. Quando o fizer, ela ainda pode ser autossuficiente ou não, caso em que outras técnicas processuais poderão lhe servir de suporte, mantida a unidade processual entre as fases de cognição e execução.

Na solução da demanda, ou melhor, a resolução do objeto litigioso ou a situação concreta social que impulsionou a propositura da ação, incumbe ao Magistrado a interpretação e aplicação do direito, de modo que o Magistrado proporcionará a concreção da norma jurídica, exprimindo operação interpretativa:

Como nem os fatos e nem o direito independem de interpretação, o material com que trabalha o juiz no processo é o resultado de uma operação interpretativa. Dada a dupla indeterminação do direito (oriunda da equivocidade dos textos e da vagueza das normas), o juiz para sentenciar tem que primeiro decidir-se a respeito de como dissipará a indeterminação inerente ao problema jurídico. Daí que a sentença depende de decisões interpretativas, sem as quais não há ainda norma a ser aplicada para solução do caso concreto. (Marinoni et al., 2017, p. 339)

Para trazer ao conhecimento do destinatário as decisões interpretativas desenvolvidas pelo Juiz-intérprete, importante que a sentença traga em seu bojo fundamentação que tenha compreensão, expondo, pela argumentação, as razões jurídicas da decisão.

Aparentemente, parece-nos lógica essa imposição, mas, na prática forense, nem sempre ela ocorre. E não apenas nas decisões judiciais. As peças processuais das partes muitas vezes também são incompreensíveis e fogem da racionalidade necessária à formulação de argumentos que dão base a pretensão.

O filtro da racionalidade - ou seja, aquilo que está submetido à razão, à intelecção, à compreensão - é uma preocupação antiga do sistema anglo-saxão. Robert Alexy (2020) anota já no prefácio de sua obra "Teoria da Argumentação Jurídica", que a Primeira Turma do Tribunal Constitucional Federal alemão, na resolução sobre o desenvolvimento do direito, de 14 de fevereiro de 1973, exigiu que as decisões dos juízes deveriam basear-se em "argumentações racionais". 
Com efeito, os elementos essenciais da sentença abarcam o relatório, a fundamentação e o dispositivo, extraindo-se essa previsão do contido no artigo 489, do Código de Processo Civil. Dessa maneira, ao decidir o Magistrado exporá as razões de fato e de direito que levaram à conclusão, mas essas razões encontram assento, na doutrina, ora sob o nome de fundamentação, ora motivação.

Ocorre que o lastro desse dispositivo é outro de envergadura superior, o artigo 93, inciso IX, da Constituição Federal, o qual também adota a noção de fundamentação, dispondo "todos os julgamentos dos órgãos do Poder Judiciário serão públicos e fundamentadas todas as decisões, sob pena de nulidade”.

Nessa perspectiva, parece-nos apropriada a utilização uniforme do termo fundamentação. Fundamentar, portanto, é ato de aportar as razões jurídicas que levaram à convicção; explica-se a eleição de determinado posicionamento dentre os dispostos pelas partes e no ordenamento jurídico. Note-se, não é apenas motivar, no sentido de dizer o motivo, é mais, é dar argumentos, contra-argumentos, demonstrar as razões do convencimento.

Quando o Juiz fundamenta, ele também expõe motivos, o que o moveu a chegar a determinada conclusão (Medina, 2021), os quais são parte integrante da própria fundamentação.

Indo além, Ronaldo Kochem (2021, p. 15-17) expõe que é necessário o acerto terminológico, na medida em que na busca do significado dos verbetes mencionados, há conjuntos de significados iguais, mas há conjuntos de significados que são próprios para cada um, denotando que esses significados individuais são mais fortes para apontar a propriedade de diferenciar os termos. Dessa maneira, segundo o autor, é necessário:

[R]edefinir a utilização de apenas um dos termos para designar a explicitação do modo pelo qual o julgador chega à determinada conclusão (motivação, no sentido de causa e de origem) e apenas de um dos termos para designar a justificação de determinada conclusão em uma base legitimadora (fundamentação, no sentido de apoiar-se em uma base).

A racionalidade, portanto, se encontrará quando se expuserem razões de fato e de direito na fundamentação, possibilitando que o discurso jurídico seja controlável pelos participantes desse diálogo instituído no arcabouço processual, como também pela sociedade. A fundamentação adequada possibilita esse controle inteligível das razões expostas, o que se diz ser um controle intersubjetivo.

Nesse sentido, pontua Wróblewski (1971, p. 412):

Rational decision is a justified decision. Rationality is relative to the amount of knowledge of the decision-maker, to his evaluations and to the rules of inference accepted by him. Justified decision is relative to the norms, evaluations and inferences taken into account by the decision-maker.

Justamente daí que a autoridade do Poder Judiciário é retirada, pois sua legitimidade é uma legitimidade argumentativa.

Indo além, sustenta Ronaldo Kochem (2021, p. 84) que "legitima-se, de um lado, pelo respeito ao direito que resulta das discussões e dos debates parlamentares e, de outro lado, pelo debate ocorrido dentro do processo, por meio do exercício do direito ao contraditório". Dentro do Estado Constitucional de Direito, a legitimidade das razões judiciais perpassa, portanto, funções de controle e de legitimidade atreladas a valores de participação e de juridicidade, esta amparada nas previsões constitucionais de relação de independência e harmonia entre os Poderes ( $\operatorname{art} .2^{\circ}$ ), submissão ao princípio da legalidade (art. $5^{\circ}$, inciso II), supremacia da Constituição (art. $1^{\circ}$, parágrafo único) e meios de controle de constitucionalidade.

É importante, neste ponto, esclarecer que o objeto do discurso judicial é dado por razões explicativas e razões discursivas (Kochem, 2021, p. 46). Sendo assim, relacionam-se as razões explicativas ao contexto de descoberta, enquanto as razões justificativas relacionam-se ao contexto de justificação. 
Sobre essa visão trataremos nesse estudo da importância de teorias da argumentação jurídica e seus aportes para a dogmática do Processo Civil, como meio de proporcionar que a sentença alcance racionalidade, como exige o papel do Poder Judiciário no Estado Democrático de Direito.

\section{Metodologia}

O trabalho de investigação realizado neste estudo conta com pesquisa para identificação de bibliografia consolidada sobre os temas interdisciplinares, das áreas a que busca questionar, aprofundar e esclarecer um paradigma preocupado com a efetivação da tutela de direito por meio do processo, visa demonstrar a preocupação de uma abordagem que esclarece o papel das razões justificativas da decisão judicial, num panorama contemporâneo. Logo, foi necessária tanto a pesquisa bibliográfica que inclui artigos científicos, dissertações e doutrina expoentes, de âmbito nacional e estrangeira, como também de decisões judiciais de nossos tribunais.

\section{O Paradigma do Pós-Positivismo e do Estado Democrático de Direito e a Influência no Papel de} Legitimidade da Decisão Judicial

A preocupação com o papel das decisões judiciais e sua legitimidade como fonte do direito, ou melhor, como concretização de interesses para uma sociedade justa, passou da evolução da escola formalista, do positivismo jurídico de Hans Kelsen, tendo como marco histórico o pós-guerra na Europa Ocidental e a redemocratização que protagonizou a Constituição Federal de 1988 e possibilitou a reaproximação entre o direito e a moral.

Para nos situar sobre o papel da interpretação no positivismo, explana Ana Luiza Rodrigues Braga (2020, p. 11) que:

Para Kelsen, "o ser humano conhece pela razão e age pela vontade" (Barzotto, 2017, p. 12). Desta feita, ao reconhecer que em todo ato de aplicação da lei existe um grau de indeterminação que demanda uma atividade interpretativa por parte do juiz, Kelsen também reconhece que dessa margem de interpretação - a famosa moldura normativa -decorre um ato de criação do direito que não está sujeito a uma teoria objetiva da moralidade, tampouco da racionalidade, mas à discricionariedade do aplicador:[...] na aplicação do direito por um órgão jurídico, a interpretação cognoscitiva (obtida por uma operação de conhecimento) do direito a aplicar combina-se com um ato de vontade em que o órgão aplicador do direito efetua uma escolha entre as possibilidades reveladas através daquela mesma interpretação cognoscitiva.

O reconhecimento da força normativa da Constituição, portanto, refletiu na necessidade de voltarmos os olhos para o processo de constitucionalização do direito, ampliando os métodos de interpretação das normas jurídicas, que, de antemão, devem guardar verificação com paradigmas constitucionais.

O pós-positivismo (também chamado de neoconstitucionalismo) é, assim, o marco filosófico a caminhar em paralelo com o Estado Democrático de Direito, agregando valores ao direito posto, ou seja, a interdisciplinariedade entre o direito e a moral, com ênfase à atribuição de função normativa aos princípios, abandonando-se a pura lógica subsuntiva.

Ressalta Luís Roberto Barroso (2005, p. 4-5):

A superação histórica do jusnaturalismo e o fracasso político do positivismo abriram caminho para um conjunto amplo e ainda inacabado de reflexões acerca do Direito, sua função social e sua interpretação. O pós-positivismo busca ir além da legalidade estrita, mas não despreza o direito posto; procura empreender uma leitura moral do Direito, mas sem recorrer a categorias metafísicas. A interpretação e aplicação do ordenamento jurídico hão de ser inspiradas por uma teoria de justiça, mas não podem comportar voluntarismos ou personalismos, sobretudo os judiciais. No conjunto de idéias ricas e heterogêneas que procuram abrigo neste paradigma em construção incluem-se a atribuição de normatividade aos princípios e a definição de suas relações com valores e regras; a reabilitação da razão prática e da argumentação jurídica; a formação de uma nova hermenêutica constitucional; e o desenvolvimento 
de uma teoria dos direitos fundamentais edificada sobre o fundamento da dignidade humana. Nesse ambiente, promove-se uma reaproximação entre o Direito e a filosofia.

Caminha-se em busca da concretização de ideais de Justiça para a solução do caso concreto.

A norma jurídica, note-se, tem sua expressão pela decisão judicial de modo que a linguagem serve para revelar o seu significado - uma aferição que é antimecanicista, não puramente abstrata. Daí por que Humberto Ávila (2007, p. 30) indica que os textos abstratos não são normas, são o objeto da interpretação, constituindo o seu resultado a norma, o seu sentido.

Ressalta, nesse sentido, Ronaldo Kochem (2021, p. 104) que:

A doutrina da justificação lógico-silogística da decisão corresponde a uma teoria positivista da aplicação do direito que, segundo Castanheira Neves, iludia o problema da real aplicação do direito ao não considerar a sua problematicidade jurídico-concreta. Ela converte um postulado político, segundo o qual só a lei pode criar o Direito e a decisão judicial deve limitar-se a aplicá-lo, em um esquema metódico lógico pretensamente aproblemático.

O Poder Judiciário, portanto, exerce papel de proeminência e, no paradigma da Jurisprudência dos Valores, a sua legitimidade é dada por meio da fundamentação das decisões. No pós-positivismo, tem abarcado mais poder, retirando-o da centralidade do Poder Legislativo, assim ao abandono da centralidade da lei e sua aplicação abstrata na maneira elaborada pelo Legislador, as decisões judiciais recebem sua legitimidade - no enfoque da separação dos Poderes - por meio da argumentação. Nesse caminho, é imprescindível dar cientificidade à justificação das decisões judiciais, assegurando a legitimidade argumentativa.

Nessa senda, ao tratar do pós-positivismo, no qual há o desenvolvimento de uma nova dogmática da interpretação constitucional, Luís Roberto Barroso (2005, p. 15) mais uma vez acrescenta:

Chega-se, por fim, à argumentação, à razão prática, ao controle da racionalidade das decisões proferidas, mediante ponderação, nos casos difíceis, que são aqueles que comportam mais de uma solução possível e razoável. As decisões que envolvem a atividade criativa do juiz potencializam o dever de fundamentação, por não estarem inteiramente legitimadas pela lógica da separação dos Poderes - por esta última, o juiz limita-se a aplicar, no caso concreto, a decisão abstrata tomada pelo legislador. Para assegurar a legitimidade e a racionalidade de sua interpretação nessas situações, o intérprete deverá, em meio a outras considerações: (i) reconduzi-la sempre ao sistema jurídico, a uma norma constitucional ou legal que lhe sirva de fundamento - a legitimidade de uma decisão judicial decorre de sua vinculação a uma decisão majoritária, seja do constituinte ou do legislador; (ii) utilizar-se de um fundamento jurídico que possa ser generalizado aos casos equiparáveis, que tenha pretensão de universalidade: decisões judiciais não devem ser casuísticas; (iii) levar em conta as consequências práticas que sua decisão produzirá no mundo dos fatos.

O desenvolvimento do pós-positivismo conduz à revaloração da ciência jurídica, trazendo o debate moral, uma moral jurídica, para a formulação da norma jurídica, em suma, pela abrangência da utilização dos conceitos indeterminados, cláusulas gerais e os princípios, nesse caso, em especial, os constitucionais.

Cite-se a perspectiva da cláusula geral; defronte a ela, o intérprete verifica plasticidade, não encontrará de per si o sentido e alcance da norma. Precisará, assim, proceder ao revolvimento dos elementos fáticos, valorá-los, integrando seu conteúdo, ou melhor: “[c]omo a solução não se encontra integralmente no enunciado normativo, sua função não poderá limitarse à revelação do que lá se contém; ele terá de ir além, integrando o comando normativo com a sua própria avaliação” (Barroso, 2005, p. 12-13).

Bem por isso, o silogismo puro com a subsunção entre lei e fato não atende aos anseios sociais, por isso se utiliza o Legislador de normas abertas, na tentativa de que a solução jurídica seja concebida a posteriori por meio de concreção.

Não se trata do abandono completo da doutrina lógica-silogística para aplicação do Direito. Reconhece-se, ao contrário, sua incompletude diante da constatação clara de que há necessidade de reintrodução de valores para a formulação da 
norma jurídica individual, particularizada pela decisão judicial. A revaloração do Direito, frente aos anseios de sua época, exige a justificação desses aspectos, cuja lógica-dedutiva pura (premissa-maior, premissa-menor e conclusão) não seria suficiente para solucionar.

Por isso, destaca Kochem (2021, p.31) que a Teoria do Direito reconhece a relevância do papel instrumental dos argumentos jurídicos, para permitir a solução dos problemas de linguagem, de indeterminação do Direito. Trazendo os aportes da Escola de Gênova, sustenta Kochem que "são três as funções da argumentação jurídica para atividade jurisdicional: identificação de significados, criação de novos significados e especificação (ou concreção) de significados identificados".

A justificação dessa concreção, por meio das decisões judiciais, instala-se em um palco, o processo, cujo auditório é formado pela sociedade e principalmente pelas partes. Indo além, auditório e atores principais se fundem, dialogam e formam a chamada comunidade argumentativa de trabalho, preocupação do modelo cooperativo de processo.

Conclui-se, portanto, que o processo de justificação da sentença conterá uma estrutura que exponha razões justificativas dotadas de argumentos, reconduzindo-nos ao desenvolvimento com premissas que levam à conclusão. Não se trata de tarefa mecânica e imediata.

Deve-se, em conclusão, verificar que as mudanças de paradigmas foram marco de transformação do Processo Civil, constituindo a concretização da tutela de direitos o fim esperado. Para que o direito processual permita essa efetivação, foi necessária a revaloração de seus institutos jurídicos.

Sintetiza Ronaldo Kochem (2021, p. 25) que:

O quadro conceitual delineado pelo reconhecimento do processo como fenômeno complexo e valorativo ilumina a problemática existente na função jurisdicional. É a partir da perspectiva centrada no processo, que a atividade jurisdicional se coloca na posição de solucionar, por meio da participação argumentativa das partes, a crise de irrealizabilidade do Direito.

Estabelecido de forma clara o fim ou a finalidade da jurisdição, é possível aperfeiçoar os meios para tanto; nisso se enquadra a Teoria da Decisão Judicial, que pressupõe justificação atenta à relevância equivalente dos argumentos das partes.

As razões judiciais somente poderão ser explicadas se as partes trouxeram argumentos sobre elas. Desse modo, precisa bem Kochem (2021, p. 165) que o direito ao contraditório, e aqui tratamos da cooperação, trata-se de um metacritério de correção da fundamentação da decisão judicial. O doutrinador destaca a importância do papel do juiz no debate:

Se as partes e o juiz não debateram a respeito da competência do juízo, da legitimidade das partes, da suficiência das custas processuais (questões processuais), isso não deverá ser objeto da fundamentação da decisão judicial. Se as partes e o juiz não debateram a respeito do sentido de um determinado dispositivo, havendo um efetivo consenso no processo a respeito da norma aplicável ao caso (premissa normativa), também não haverá fundamentação quanto a isso. Se não se debateu a respeito da validade da norma (premissa normativa), tampouco. Se as partes e o juiz não debateram a respeito da verdade dos fatos, restando incontroversos os fatos afirmados na inicial, ou da possível qualificação desses (premissa fática), também aí não haverá fundamentação judicial sobre esse aspecto.

Em face do conteúdo do direito ao contraditório, todavia, não se poderá pensar - a partir das afirmações acima - que o processo é coisa apenas das partes, que a validade das normas ou o conteúdo dado aos dispositivos seria decidido a cada caso pelo comportamento das partes, privilegiando o particularismo jurídico. Tampouco se poderá contrapor o ponto aqui sustentado com a questão a respeito da verdade negociada no Processo Civil. O que aqui se sustenta é que o Processo Civil, entendido como actum trium personarum, garante por meio do direito ao contraditório a possibilidade de qualquer uma das partes e também o juiz provocar o debate a respeito de questões e premissas nos limites dados pelo formalismo processual.

Ocorre que, como defende Kochem (2021, p. 23), é preciso retirar a visão que mantém o juiz no topo da relação processual, num modelo assimétrico de processo, cujo estudo da ciência reside apenas na jurisdição. Isso porque, não se garante que haja entre partes e juiz um caminho equilibrado e cooperativo, para se chegar à decisão. 
Porém, o conhecimento prévio sobre os institutos jurídicos e dispositivos the inerentes que orientarão a decisão judicial garante a ausência de surpresas e possibilita o debate, ao fim e ao cabo para possibilitar influir na solução da causa.

Por isso, acrescenta Kochem (2021, p.154) que essa roupagem do direito ao contraditório reforça uma teoria da jurisdição que tenha aspecto reconstrutivo não apenas dos atos, mas principalmente do Direito, a partir do papel argumentativo das partes e da decisão com relação ao direito aplicável. Ao arremate, sustenta o autor que é somente a partir da norma reconstruída que se define, então, quais são os fatos relevantes para a causa.

\section{O Dever Judicial de Fundamentação Analítica}

A conjugação de esforços no diálogo entre as partes e o Juiz reflete necessariamente na atenção a ser dada aos liames do desenvolvimento justificação da sentença, de modo que a interpretação e aplicação do raciocínio judicial se revelem coerentes ao dever de fundamentação. Temos, portanto, a exigência não apenas de coerência interna dos argumentos da decisão judicial, como também a exigência externa de análise dos argumentos suscitados em contraditório/cooperação.

Há muito o artigo 93, inciso IX, da Constituição Federal, traz a previsão de que "todos os julgamentos dos órgãos do Poder Judiciário serão públicos, e fundamentadas todas as decisões, sob pena de nulidade". Frente a isso, os artigos 11 e 489, $\S 1^{\circ}$, do Código de Processo Civil, vieram a densificar a maneira como essa fundamentação, que tem por lastro a própria publicidade, seria efetivada no âmbito processual civil, dispondo:

Art. 11. Todos os julgamentos dos órgãos do Poder Judiciário serão públicos, e fundamentadas todas as decisões, sob pena de nulidade.

Parágrafo único. Nos casos de segredo de justiça, pode ser autorizada a presença somente das partes, de seus advogados, de defensores públicos ou do Ministério Público.

(...)

Art. 489. São elementos essenciais da sentença:

I - o relatório, que conterá os nomes das partes, a identificação do caso, com a suma do pedido e da contestação, e o registro das principais ocorrências havidas no andamento do processo;

II - os fundamentos, em que o juiz analisará as questões de fato e de direito;

III - o dispositivo, em que o juiz resolverá as questões principais que as partes lhe submeterem.

$\S 1^{\circ}$ Não se considera fundamentada qualquer decisão judicial, seja ela interlocutória, sentença ou acórdão, que:

I - se limitar à indicação, à reprodução ou à paráfrase de ato normativo, sem explicar sua relação com a causa ou a questão decidida;

II - empregar conceitos jurídicos indeterminados, sem explicar o motivo concreto de sua incidência no caso;

III - invocar motivos que se prestariam a justificar qualquer outra decisão;

IV - não enfrentar todos os argumentos deduzidos no processo capazes de, em tese, infirmar a conclusão adotada pelo julgador;

V - se limitar a invocar precedente ou enunciado de súmula, sem identificar seus fundamentos determinantes nem demonstrar que o caso sob julgamento se ajusta àqueles fundamentos;

VI - deixar de seguir enunciado de súmula, jurisprudência ou precedente invocado pela parte, sem demonstrar a existência de distinção no caso em julgamento ou a superação do entendimento.

$\S 2^{\circ}$ No caso de colisão entre normas, o juiz deve justificar o objeto e os critérios gerais da ponderação efetuada, enunciando as razões que autorizam a interferência na norma afastada e as premissas fáticas que fundamentam a conclusão.

$\S 3^{\circ}$ A decisão judicial deve ser interpretada a partir da conjugação de todos os seus elementos e em conformidade com o princípio da boa-fé.

Ressaltam Marinoni et al. (2017, p. 342) que houve atenção especial ao dever de fundamentação analítica no Código de Processo Civil de 2015, pois, além de relacioná-lo ao direito ao contraditório, houve a expressa menção do que não seria uma decisão fundamentada. 
Portanto, os artigos 93, inciso IX, da Constituição Federal, e artigos 11 e 489, do Código de Processo Civil, ainda, devem ser lidos com atenção ao densificado nas normas fundamentais do processo civil, em especial o previsto nos artigos $7^{\circ}$, $8^{\circ} 9^{\circ}$ e 10, do Código de Processo Civil:

Art. $7^{\circ}$ É assegurada às partes paridade de tratamento em relação ao exercício de direitos e faculdades processuais, aos meios de defesa, aos ônus, aos deveres e à aplicação de sanções processuais, competindo ao juiz zelar pelo efetivo contraditório.

Art. $8^{\circ}$ Ao aplicar o ordenamento jurídico, o juiz atenderá aos fins sociais e às exigências do bem comum, resguardando e promovendo a dignidade da pessoa humana e observando a proporcionalidade, a razoabilidade, a legalidade, a publicidade e a eficiência.

Art. $9^{\circ}$ Não se proferirá decisão contra uma das partes sem que ela seja previamente ouvida.

Parágrafo único. O disposto no caput não se aplica:

I - à tutela provisória de urgência;

II - às hipóteses de tutela da evidência previstas no art. 311, incisos II e III ;

III - à decisão prevista no art. 701 .

Art. 10. O juiz não pode decidir, em grau algum de jurisdição, com base em fundamento a respeito do qual não se tenha dado às partes oportunidade de se manifestar, ainda que se trate de matéria sobre a qual deva decidir de ofício.

Dessa forma, para que a decisão não recaia sob os vícios de nulidade, imprescindível que ela se atenha à necessidade de contraditório, em cujo diálogo se insere também o magistrado, como expressamente passou a determinar nosso Código de Processo Civil.

Abordarmos o princípio em tela, que se trata de uma norma fundamental do Processo Cvil, exige mencionar que a publicidade e o contraditório/cooperação são sua base, pois incumbe ao Julgador pronunciar-se claramente sobre o material fático e jurídico trabalhado no arcabouço processual. O dever de fundamentação analítica, portanto, corresponde à necessidade de abordar as razões justificativas que sustentam a convicção do julgador, sob um aspecto positivo, qual seja, os limites do diálogo com as partes e as normas fundamentais do Processo Civil, e outro negativo, como prevê o parágrafo $1^{\circ}$, do art. 489, do Código de Processo Civil.

Nesse desenvolvimento, para que uma decisão seja considerada fundamentada, necessário que a enunciação das escolhas desenvolvidas pelo órgão judicial individualize as normas aplicáveis, promova a análise das alegações de fato, proceda a qualificação jurídica do fato e demonstre as consequências jurídicas dela. Prosseguindo, incumbe ao Magistrado demonstrar o contexto dos nexos de implicação e coerência entre esses enunciados (Marinoni et al., 2017, p. 343).

O dever de fundamentação analítica, ao que atrelado a necessidade de individualização das normas aplicáveis, incide sobre o que se considera como uma decisão não fundamentada, de modo que se repele haja a limitação à indicação, à reprodução ou à paráfrase de ato normativo (inciso I, do $\$ 1^{\circ}$, art. 489, CPC). Assim, é preciso esclarecer qual o vínculo, inferência, entre as normas aplicáveis e o caso concreto.

A preocupação é a mesma estampada nos incisos V e VI, pois não se deve afirmar a aplicação ou afastar "precedentes qualificados", assim considerados as súmulas, os acórdãos em recursos repetitivos ou com repercussão geral (conforme os denomina o Regimento Interno do Superior Tribunal de Justiça), mas não identificar como as premissas normativas e fáticas são semelhantes ou distinguem-se.

Como já se abordou, o dever de cooperação realiza a moldura, a dimensão de argumentos trabalhada no bojo do processo, a partir disso cria-se a legítima expectativa das partes de que a decisão não se fundará em razões que já previamente não tenham sido debatidas, sobre as quais o material e suporte fático tenha sido alvo de produção probatória. Portanto, "invocar motivos que se prestariam a justificar qualquer outra decisão" (inciso III) ou "não enfrentar todos os argumentos deduzidos no processo capazes de, em tese, infirmar a conclusão adotada pelo julgador" (inciso IV), revela ser desprovida de 
fundamentação a ausência de razões não tenham elo com o debate, se relacionem de forma genérica e padronizada ou mesmo não abarquem argumentos de influência.

Por fim, há a necessidade de individualização da norma geral, com a indicação da premissa normativa, sendo que os textos legais que possuem cláusulas gerais, espécies de conceitos indeterminados (inciso II, do mesmo dispositivo), passem pelo processo de concreção, em virtude da indeterminação normativa.

A dupla indeterminação do Direito, portanto, é superada a partir da verificação de que o Julgador haverá de formular mais de uma decisão interpretativa e critérios norteadores de lógica-argumentativa trazem aparato metodológico e pragmático para alcançar a clareza da fundamentação, uma fundamentação analítica, amparada em racionalidade por ser dotada de argumentos com elo normativo no Direito vigente.

A decisão judicial, note-se, estabelece um discurso jurídico, que é antecedido pela atividade interpretativa do Magistrado. Delimitam-se, pois, duas fases: o contexto ou processo da descoberta (context of discovery) e o contexto ou processo da justificação (context of justification) ${ }^{1}$.

Com efeito, antes, deve-se mencionar que a divisão dos chamados contextos da atividade judicial não é um conceito próprio da Ciência do Direito, mas advém de estudos envoltos à teoria geral do conhecimento (mais propriamente, a Psicologia e Epistemologia).

Segundo Kochem (2021, p. 47-49), foram os estudos de Rudolf Carnap, Karl Popper e Hans Reichenbach que vieram a cunhar as expressões context of discovery e context of justification para distinguir os objetos da ciência da Psicologia e da Epistemologia. Nessa divisão, a Epistemologia seria incumbida pela construção do contexto de justificação, pois seria o estudo da reconstrução racional do pensamento, com interconexões lógicas, mas as operações psicológicas seriam caminhos vagos e flutuantes, que contêm saltos que racionalmente não poderiam ser explicados.

Na Teoria do Direito, o reconhecimento da distinção se marca aos movimentos de crítica ao Positivismo Jurídico (Kochem, 2021, p. 51). Sendo assim, Michele Taruffo (2015, p. 17) delineia que:

[O] equivalente judiciário do context of discovery tem características estruturais próprias: articula-se no tempo, implica síntese de diversos fatores, procede por abduções e por trial and error, percorre caminhos que depois são abandonados, inclui influência de fatores psicológicos e ideológicos, implica juízos de valor e pode, ainda, compreender a participação de várias pessoas, como ocorre em todas as hipóteses nas quais a decisão é dada por colégio de juízes. De outra banda, o equivalente judiciário do contexto of justification, ou seja a motivação da sentença, tem características diferentes: ocorre quando a fase decisória já está de toda a sorte exaurida, com a decisão final já formulada; pode ser obras de pessoas diferentes daquelas que formularam a decisão e - normalmente - de uma só dessas; não tem o escopo de formular escolhas, mas de mostrar que as escolhas feitas eram 'boas'; tem estrutura argumentativa e não heurística; tem função justificativa; é um 'discurso' - e, portanto, uma entidade linguística - e não um iter psicológico; funda-se em argumentos com validade tendencialmente intersubjetivos; é logicamente estruturada; pode incluir inferências dedutivas e indutivas, mas não abdutivas, e assim por diante.

Essas duas fases são nominadas pela doutrina de Alexy (2020) como justificação interna e justificação externa. Ressalta, ainda, que as premissas que não partem do direito positivo têm especial importância na exigência da justificação interna e fundamentá-las é tarefa para a justificação externa. De modo que, "isso aumenta a possibilidade de reconhecer e criticar erros. Acrescentar ou apresentar regras universais facilita a consistência da decisão e contribui, por isso, para a justiça e para a segurança jurídica” (Alexy, 2020, p. 203).

Surge, portanto, dentro do dever de fundamentação analítica, a necessidade de apurar a forma como os argumentos serão trabalhados na sentença, como produto da atividade interpretativa do Julgador. Portanto, é imprescindível a leitura desse dever com teorias que demonstrem e apurem o contexto de justificação, onde se situa a atividade-ato sentença.

${ }^{1}$ Robert Alexy (2020, p. 202) se refere ao processo de descoberta e ao processo da justificação, ao analisar a justificação interna. Enquanto, Michelle Taruffo (2015, p. 17) as designa como contexto de descoberta e contexto de justificação. 


\section{Considerações Finais}

Conclui-se, dessa maneira, pela importância das teorias da argumentação jurídica para a teoria da decisão judicial. Com o retorno da valoração, da moral, para o processo de elaboração da norma jurídica, sobretudo à frente da própria indeterminação de conceitos legais, aparece a discussão na metodologia jurídica de como a decisão judicial poderá ser fundamentada, constituindo-se em "reflexão sobre a atividade discursiva sob o ponto de vista ético" (Camargo, p. 134-135).

De importância primária se estamos à frente de um marco em que o Poder Judiciário exerce papel fundamental na concretização de direitos, na qual as valorações não partem da lógica subsuntiva, impõe-se o desenvolvimento de novos meios de justificação das decisões judiciais, em que a preocupação com a análise do objeto litigioso delimitado pelas partes e construído cooperativamente com o Juiz, encontre papel de destaque na atividade judicial-construtiva corporificada na sentença, seara própria desenvolvida pelo pensamento tópico e ulteriores construções de teorias preocupadas com a argumentação jurídica.

Temos que ter em vista que a Epistemologia jurídica, ou seja, o estudo dos fundamentos da ciência jurídica, revela que a perspectiva filosófica é a base para a dogmática, o caminho para a compreensão do texto normativo. E, nesse caminho, se demonstrou que a linguagem é essencial ao Direito, sua própria essência é a demonstração por meio de signos para exprimir os comandos normativos, posições doutrinárias ou precedentes.

A preocupação com a linguagem sobressai-se na decisão judicial, pois está atrelada à interpretação e produção da norma jurídica.

Por assim, Eros Grau (2002, p. 76) leciona a interdependência entre a interpretação e a aplicação, pois interpretar é a tarefa de concretude do direito, sua própria aplicação:

Interpretação e aplicação não se realizam autonomamente. (...) O intérprete discerne o sentido do texto a partir e em virtude de um determinado caso dado [Gadamer 1991:397]; a interpretação do direito consiste em concretizar a lei em cada caso, isto é, na sua aplicação [Gadamer 1991:401]. Assim, existe uma equação entre interpretação e aplicação: não estamos, aqui, diante de dois momentos distintos, porém frente a uma só operação [Marí 1991:236]. Interpretação e aplicação consubstancia um processo unitário [Gadamer 1991:381], se superpõem.

Nessa medida, identifica Alexy (2020, p. 17) que a ausência de possibilidade da decisão judicial, tida como "um enunciado normativo singular", decorrer logicamente do direito posto e vigente, tem preponderantes quatro motivos: (1) imprecisão da linguagem do Direito; (2) possibilidade de conflito entre normas; (3) possibilidade de haver casos que não se amoldem em regulamentação jurídica pré-existente; e, (4) em casos especiais, a possibilidade de contrariedade à lei.

No contexto pós-positivista, envolto que estamos no neoconstitucionalismo, Barroso (2005, p. 15) destaca que a relação entre o texto legal e o Juiz, no âmbito da interpretação, superou os métodos tradicionais de Savigny, que deixaram de ser suficientes ao tempo da valoração que o direito contemporâneo impõe:

Com o avanço do direito constitucional, as premissas ideológicas sobre as quais se erigiu o sistema de interpretação tradicional deixaram de ser integralmente satisfatórias. Assim: (i) quanto ao papel da norma, verificou-se que a solução dos problemas jurídicos nem sempre se encontra no relato abstrato do texto normativo. Muitas vezes só é possível produzir a resposta constitucionalmente adequada à luz do problema, dos fatos relevantes, analisados topicamente; (ii) quanto ao papel do juiz, já não lhe caberá apenas uma função de conhecimento técnico, voltado para revelar a solução contida no enunciado normativo. O intérprete torna-se co-participante do processo de criação do Direito, completando o trabalho do legislador, ao fazer valorações de sentido para as cláusulas abertas e ao realizar escolhas entre soluções possíveis.

Nesse carrear, é notório que, como pontuou Maria Helena Diniz (2010, p. 169), o pensamento é articulado pela linguística, pois seus signos constituem o essencial da comunicação humana, de modo que "a ciência jurídica encontra na linguagem sua possibilidade de existir". 
$\mathrm{Na}$ indeterminação do texto normativo, como pela presença de vagueza normativa, surge o problema de como a decisão judicial poderá ser fundamentada.

Para o desenvolvimento do raciocínio judicial há influência dos cânones de interpretação. Mesmo se admitindo a importância deles, não se pode descartar que há controvérsia quanto a sua catalogação (ou seja, quais são, em que número o são e mesmo se existe hierarquia entre eles). Desse modo, o resultado será encontrado a depender de como são utilizados por cada intérprete e não há nisso segurança jurídica, não sendo suficientes por si mesmas para fundamentação de decisões jurídicas (Alexy, 2020, p. 19).

A valoração, ou juízo de valor, contida na decisão judicial é o campo de atuação em que o Julgador pode eleger entre diversas soluções, realizada várias decisões interpretativas, a possibilidade de constituir aspectos de racionalidade para ela é o objeto das teorias da argumentação jurídica.

Identificando o problema, Robert Alexy (2020, p. 22) também evidencia a importância de uma resposta como direcionamento:

Dela depende, ao menos em partem a decisão sobre o caráter científico da jurisprudência. Ela tem, além disso, um relevante peso em relação ao problema da legitimidade da regulação dos conflitos sociais mediante decisões judiciais. Isso porque, quando subjazem valorações às decisões dos tribunais (ainda que essas valorações não se possam fundamentar racionalmente), as convicções normativas faticamente existentes, ou melhor as decisões de um grupo profissional formam a base, em muitos casos, não ulteriormente legitimada nem legitimável, de tais regulações de conflitos.

Com efeito, a evolução da história da filosofia comum aos tempos e pensamentos se deu na perspectiva da filosofia do ser, filosofia da consciência e filosofia da linguagem. É o giro linguístico o marco de transição entre os dois últimos paradigmas e para ele contribuiu os estudos de Ludwig Wittgenstein. O mencionado filósofo austríaco contribui para o giro linguístico em segundo momento de seus estudos, inclusive sua trajetória e aportes são denominados de Primeiro Wittgenstein, em que estuda os planos sintático e semântico da linguagem, e Segundo Wittgenstein, em que demonstra a importância do contexto e uso do signo linguístico para a compreensão. Somente a análise de como a linguagem é empregada em seu contexto, costumes e concordâncias de uma comunidade, permite a sua compreensão.

Nessa medida, em Wittgenstein, a linguagem, passa a ser vista em uma função verdadeiramente pragmática. De modo que as conjunturas, ou diferentes jogos de linguagem, é que apresentarão o sentido sintático e semântico do enunciado, possibilidade alcançada somente com a dimensão pragmática (Pereira, 2019, p. 29).

Com os aportes da filosofia comum da linguagem, na teoria do direito, duas tradições se despontam: a analítica e a hermenêutica (ou continental). Ambas têm por escopo o estudo da linguagem no discurso jurídico, mas pretendem desenvolver lineares diversos para a atribuição do sentido aos enunciados e à tarefa do Magistrado-intérprete nesse trabalho.

Sob os influxos de estudiosos da filosofia da linguagem do segundo Wittgenstein e da filosofia analítica de Bertrand Russel, tem-se a teoria analítica do direito que possui três diferentes expressões: a orientação sociológica, presente no Realismo Jurídico norte-americano e escandinavo; a orientação lógico-analítica, marcadamente anglo-saxã; e a escola italiana de filosofia do Direito (Dobrowolski, 1997, p. 16-20).

Também voltada a se afastar da técnica subsuntiva pura e aos influxos da filosofia da linguagem do segundo Wittgenstein, hermeneutas utilizam-se, por sua vez, dos conceitos da filosofia hermenêutica de Schleirmacher, Gadamer e Heidegger.

Note-se, como aspecto comum, a relevância do pensamento voltado à interpretação/aplicação do direito a partir do problema concreto posto em debate, essencialmente um pensamento tópico como ponto de partida. Outrora, a importância da Tópica, de Vieweg, que em 1953, ao seu tempo, retomou as ideias de Aristóteles e Cícero, num contexto de ruptura com o método subsuntivo, defendendo a construção de normas, para solução de problemas contemporâneos, a partir dos problemas 
num confronto de argumentos e não de maneira previamente estabelecida pelo texto legal, como se fosse possível ex ante delimitar todas as soluções aos problemas jurídicos.

As ideias da Tópica de Vieweg, portanto, contribuem para o desenvolvimento das teorias da argumentação jurídica ao promover a necessidade de que o jurista justificasse o seu raciocínio a partir dos topoi, em um giro argumentativo (Pereira, 2019, p. 43). Em conclusão, Vieweg contribui ao defender que a racionalidade da decisão advém do próprio processo argumentativo que conduz à conclusão e a fundamenta, demonstrando a conveniência dos pontos de partida ou topoi (Dobrowolski, 1997, p. 25).

Ocorre que a Tópica não se constituiu em método, em maneira isolada de aplicação da ciência jurídica, pois falta-lhe a aplicação sistemática, essencial à dogmática jurídica, podendo se afastar em muito da segurança esperada na Ciência Jurídica. Com ela, perde-se muito de sistematização por ser essencialmente casuística. Porém, mesmo que intrínseca ao pensamento filosófico analítico, pode-se visualizar que tem sua influência sobre o processo hermenêutico, caminhando em conjunto para a formação de um círculo hermenêutico.

No desenvolvimento das teorias contemporâneas da argumentação jurídica, houve primordial contribuição de Chaïm Perelman, pela nova retórica. Isso porque, de acordo com Pereira (2019, p. 43), ao realizar uma releitura da retórica aristotélica, Perelman teria defendido justamente o abandono da lógica subsuntiva do positivismo jurídico, em prol de uma lógica argumentativa, em que se busque o convencimento do auditório sobre a aceitabilidade e razoabilidade da decisão, consistente essa num discurso.

Os estudos da filosofia analítica descortinaram-se em teorias que são influência para a nossa dogmática, em especial o atual Código de Processo Civil, no concernente a decisão judicial. Em especial, são as denominadas por Manuel Atienza (2017, p. 31), como decorrentes dos estudos a partir de 1970, as teorias standards, destacando-se Robert Alexy e Neil MacCormick.

Carlos Frederico Bastos Pereira (2019, p. 44) identifica dois pilares fundamentais nesses dois autores: (1) uma análise quanto ao ponto de vista interno do aplicador, que não tem preocupação teórica apenas, mas foco na razão prática, de modo que a correção do discurso jurídico se dá nas decisões tomadas em casos concretos; (2) quanto ao ponto de vista da justificação das decisões judiciais, combate à discricionariedade e neutralidade cientifica do positivismo. Valorações nessa perspectiva são inevitáveis, mas não devem ser apresentadas segundo suas conviç̧ões pessoais, morais, religiosas; a Ciência do Direito deve, portanto, se preocupar em como devem ser justificadas as decisões judiciais (plano do dever-ser), e não apenas como foram (plano do ser).

Retomando a ideia dos contextos de descoberta e de justificação, o pensamento da filosofia analítica é sintetizado na seguinte passagem de Marinoni et al. (2017):

Em termos jurídicos, porém, pouco importa saber quais foram os motivos reais que determinaram a decisão judicial nesse ou naquele sentido. Em outras palavras, não interessam as razões psicológicas que levaram o juiz a decidir. O que interessa é saber se existem ou não razões jurídicas que suportam validamente dentro da ordem jurídica a tomada de decisão. Em outras palavras, interessa a justificativa da decisão judicial - importam as razões oriundas do sistema jurídico capazes de justificar a decisão.

Para a corrente hermenêutica, porém, a compreensão é também fator de legitimidade da decisão judicial. Nesse desenvolvimento, o poder de compreender traço essencial da hermenêutica filosófica de Hans-Georg Gadamer (2003, p. 407), atrelado ao poder de interpretar e o poder de aplicar, e implicam que os fatos (o problema) serão interpretados juntamente com o texto objeto da interpretação, numa relação de mutualidade, cuja aplicação desembocará na norma, externada pela sentença.

Esse aporte é extraído e destacado da teoria gadameriana para pontuar a conexão entre fato e norma, inexistindo interpretação isolada dos textos normativos sem os fatos envolvidos (problema). Desenvolve-se, então, o círculo hermenêutico; 
nele, o intérprete estará atrelado ao contexto social em que o texto está inserido (jogos de linguagem) e, uma vez vinculado também à tradição - que são os significados anteriores dados pela ordem jurídica àquele mesmo signo.

Para a abordagem hermenêutica do direito, explica Pereira (2019, p. 67):

A fundamentação hermeneuticamente adequada das decisões judiciais é aquela que permite o controle intersubjetivo da interpretação jurídica por meio da compreensão dos textos jurídicos à luz da facticidade (circunstâncias do caso concreto) e da historicidade (tradição jurídica).

(...)

A compreensão funciona, portanto, como instrumento de controle intersubjetivo da decisão, justamente, porque a intersubjetividade (linguagem pública) acaba constrangendo a subjetividade do interprete (linguagem privada), impondo que o mesmo revisite o manancial normativo à sua disposição para verificação do sentido atribuído ao texto legal pela tradição e a necessidade de eventual ajuste ao caso concreto (coerência e integridade do direito).

De toda sorte, possível a complementariedade e o diálogo entre as duas correntes.

Inclusive, Robert Alexy defende, em sua obra "Teoria da Argumentação Jurídica", que a tarefa de sua Teoria é a de propor regras que sejam de um lado tão fracas, ou seja, que tenham tão pouco conteúdo normativo, que indivíduos com concepções normativas totalmente diferentes possam estar de acordo com elas. Mas, ainda assim, sejam tão fortes, que uma discussão pautada sobre elas possa ser qualificada como "racional" (2020, p. 30).

José Reinaldo de Lima Lopes (2016, p. 211), então, destaca que houve uma terceira linha que buscou aproximar ou mesmo integrar as duas correntes filosóficas, ainda com a reflexão sobre a ética do discurso.

Desenvolvendo o seu raciocínio, Lopes (2016, p. 212-213) ressalta que as mencionadas correntes pressupõem que o agente domine minimamente o sentido do que expressa e possa então justificar aquilo que faz. Portanto, a ação humana para que aconteça está implicada num discurso. Na filosofia hermenêutica o destaque se dá para a percepção de que o agente está participando de uma tradição, de modo que isso o constrange a participar desse contexto e não realizar isoladamente (ao seu jargão: solipsisticamente). Ao passo que para a analítica, o sentido das atividades humanas é dado por uma linguagem objetiva, sendo ela um artefato que permite o pensamento em comum, sendo apreendida e compreendida segundo o contexto ou uso em que inserida.

Nessa medida, Almeida (2011, p. 56) observa que, em certos casos, invocar a coerência normativo-intencional ou a integridade do direito é bastante para sustentar a fundamentação das decisões judiciais. Ocorre que há infindáveis exemplos em que o Juiz se defronta com conceitos jurídicos indeterminados, sendo imprescindível a metodologia jurídica para suprí-los, concretizá-los.

Continua Almeida (2011, p. 57-58) que isso não representa incompatibilidade com o círculo hermenêutico, tampouco em apressada concepção de "morte" do método. Isso, pois o processo de realização normativa do direito não é um ato simplesmente hermenêutico. Mas, sim, esse constitui-se em um passo entre vários outros, pressupondo justificação adequada dos argumentos lançados no ato decisório. A correção do discurso e a pretensão de validade, segundo afirma, implica na necessidade de um método, ao passo que a aplicação do direito, é fenômeno complexo marcado de momentos metodológicos de concretização.

Segundo o autor, distinguir, assim, argumentos válidos de inválidos, corretos de incorretos, devem passar por regras de linguagem, tais como as propostas por Manuel Atienza e Alexy: neste, a regra da não contradição, a regra geral da fundamentação e o princípio da universalidade; naquele, regras fundamentais (não contradição, sinceridade, universalidade, uso comum da linguagem); regras da razão (regra geral de fundamentação, igualdade de direitos, universalidade e não coerção); regras sobre a carga de argumentação; formas dos argumentos; regras de fundamentação; e regras de transição.

Conclui Bruno Torrano Amorim de Almeida (2011, p. 58): 
A decisão judicial é, nesses termos, ato jurídico que busca a realização normativa mediante critérios de validade que emanam do próprio ordenamento jurídico. A mera menção à hermenêutica filosófica e seu papel na concretização judicial de princípios é indiscutivelmente insuficiente para desvendar, com o rigor necessário, qual o melhor direito aplicável à espécie, porque não procede, sem o método da argumentação jurídica, à verificação validante dos seus próprios fundamentos. Disso resulta a necessária incidência dos fatores supramencionados e de regras de linguagem que verificam o encadeamento lógico e a não contradição entre as partes do argumento, tudo com o objetivo de estabelecer a correção procedimental de eventuais deficiências na regulação da matéria decidenda.

Aliás, abordando a existência de discricionariedade judicial, tão açoitada pela filosofia hermenêutica, Ronaldo Kochem (2021, p. 41) destaca que essa atividade judicial de reconstrução do aspecto jurídico e fático passa por processo de escolha entre diferentes alternativas, vinculadas a realização de cognição, valoração e escolhas dentre as fontes normativas e provas. Destaca, acima de tudo, não ser incompatível com a visão analítica o reconhecimento do círculo hermenêutico. Explica o autor:

Aproximando-se de uma abordagem prática, pode-se afirmar, sem nenhuma ofensa ao reconhecimento analítico dos diferentes elementos sujeitos a controle de racionalidade no exercício da jurisdição, que o processo de decisão não se realiza em etapas estanques. Pelo contrário, como é ressaltado pela doutrina que cuida do iter decisório, a decisão quanto à norma aplicável pressupõe determinados fatos e a decisão quanto aos fatos relevantes do caso depende da norma aplicável. Por isso, pode-se dizer que a decisão judicial é tomada em um procedimento de tentativa e erro (trial and error), a que por vezes chamam de círculo hermenêutico ou espiral hermenêutica.

Veja-se, portanto, a importância da conjugação entre ambas as correntes e não a exclusão de uma por outra, pois o nosso sistema processual não pode estar amarrado a uma única postura filosófica que fosse capaz de engessá-lo e desaguar em ausência de efetividade procedimental e tutela dos direitos.

Bem assim, chamou a atenção Ovídio Araújo Baptista da Silva (2005, p. 79) que "[n]em somente interpretação, nem, ao contrário, apenas 'decisionismo'. A argumentação exerce, no processo judicial, uma função complementar da interpretação. Tanto mais se argumenta, melhor hermeneuticamente se compreende". Para ele, "quanto mais explica, melhor compreende".

A decisão judicial contém em si, portanto, a expressão de argumentos (explicação) sobre a interpretação realizada (compreensão), concretando a norma jurídica individual, a partir do diálogo realizado pelas partes.

Note-se, porém, que há importância primordial na visão da decisão judicial como discurso, isso porque é por meio dele que as razões judiciais serão apresentadas, razões essas que se prestam a justificar os critérios normativos, as provas escolhidas, os suportes fáticos que foram reconstruídos no bojo processual, a serem demonstrados em atenção ao dever de fundamentação analítica. Conclui-se pela preponderância das razões justificativas sobre as razões ditas explicativas; ou ainda, do contexto de justificação sobre o contexto de descoberta para o Direito.

Com efeito, as razões explicativas descrevem as relações causais ocorridas no contexto de descoberta para as conclusões da decisão judicial. Ocorre que estão atreladas a fenômenos da psicológicos passados no intelecto do Magistrado e que não se prestam para dar suporte aos interesses do Direito, de que área for, não podendo ser controlados aspectos sociológicos, culturais, experiências anteriores individuais de cada Magistrado para cada decisão judicial elaborada.

Esclarece Kochem (2021, p. 94):

As razões da decisão não devem ter um caráter de explicação do processo heurístico de tomada de decisão, porque o que se pretende avaliar é a estrutura que suporta a decisão com base em critérios jurídicos intersubjetivamente controláveis. Uma motivação da decisão, entendida como tal a exposição de razões explicativas, não vincula a avaliação a critérios intersubjetivos, mas a critérios subjetivos. Remeter a decisão jurídica para a psicossociologia 'deixa inconsiderado aquilo mesmo que a especifica (e diferencia) essa decisão como decisão jurídica, o que lhe confere juridicidade e assim um sentido normativo'. É por conta desse sentido normativo que se exige uma fundamentação também normativa, a partir da qual o juiz justifica em que medida sua decisão respeitou a lei e o Direito.

(...) 
Como indicado pelas correntes de realismo jurídico (e também pelo movimento do direito livre), a resolução dos problemas jurídicos ocorre de forma, ao menos parcialmente, intuitiva, na qual não se diferencia o erro do conhecimento correto. Por isso, a exposição dessas operações mentais não permitem uma validação racional.

Um exemplo de Kantorowicz sintetiza bem o ponto em questão: um tribunal de apelação que examina uma decisão absurda de um juiz de primeira instância que é explicável (e tão somente explicável) pelo fato de o juiz estar intoxicado ou insano no momento da decisão deve ser mantida? Segundo o autor, a decisão deverá ser reformada porque não pode ser razoavelmente justificada com base no Direito, "e essa é a única questão que interessa para a corte de apelação'. A explicação da tomada de decisão, com a apresentação das relações de causa e efeito pelas quais sobreveio, não tem relevância para fins de avaliação da decisão judicial.

A decisão judicial, ao externar contexto de justificação, dotada de razões justificativas, contém argumentos e, por sua vez, ressalta os interesses do Direito ao trazer critérios normativos, com sustentação no arcabouço processual, inferidas no diálogo com argumentos das partes. Somente essas razões podem nos reconduzir à aferição de critérios de racionalidade, permitindo a filtragem de controle e legitimação frente ao ordenamento jurídico. Ao passar por esse filtro de controle intersubjetivo, se o Julgador se afasta delas, os meios endoprocessuais permitirão que haja recondução.

Dessa maneira, desmistificado que a jurisdição se desenvolve de forma asséptica a valores, "a doutrina da justificação deve responder a fim de permitir o controle sobre os aspectos não lógicos da decisão" (Kochem, 2021, p. 106).

Os estudos das teorias da argumentação jurídica, pelas escolas que se formaram, contribuem para a formação de paradigmas para permitir controle da decisão judicial, culminando em garantir que o dever de fundamentação analítico propicie verificar a sentença como ato de inteligência, declaração e resposta (Medina, 2021). É dizer:

Como ato de inteligência, envolve a exposição de como o juiz chegou à norma com base na qual o problema haverá de ser solucionado e de como o juiz compreendeu os fatos, à luz das alegações das partes e das provas. Trata-se de dar uma resposta às partes, como é evidente (cf. comentário a seguir), e também permitir que o rigor do raciocínio desenvolvido na decisão possa ser submetido ao controle de outras instâncias judiciais. O alto grau de indefinição dos fatos sociais e do direito acaba deslocando para o processo o momento em que se revela com exatidão o sentido da norma, de modo que seu significado mais preciso é obtido ao se interpretar/aplicar o direito aos fatos. A declaração veiculada na decisão judicial, assim, desempenha função relevante para a segurança do direito, na medida em que contribui para a construção do sentido da norma jurídica (Medina, 2021).

Com esses pressupostos, temos um paradigma que se distancia da visão pura de que o direito teria soluções únicas, ante o problema da indeterminação do texto, pois se parte do pressuposto que o processo de argumentação é que vai construir a norma jurídica concreta, a solução do problema, que permitirá a efetivação da tutela por si ou por meios executivos.

\section{Referências}

Almeida, B. T. A. (2011). Da hermenêutica filosófica à correção procedimental das decisões judiciais. Revista CEJ, 52, 52-60.

Ávila, H. (2007). Teoria dos Princípios: da definição à aplicação dos princípios jurídicos. (7a ed.) Malheiros.

Silva, O. A. B. da. (2004). Verdade e Significado. Porto Alegre: Revista Magister de Direito Civil e Processual Civil, 1, 79-97.

Barroso, L. R. (2005). Neoconstitucionalismo e constitucionalização do Direito (O triunfo tardio do direito constitucional no Brasil). Revista Direito Administrativo $G V, 240,1-42$, http://bibliotecadigital.fgv.br/ojs/index.php/rda/issue/view/2473.

Braga, A. L. R. (2020). Relativismo moral em Kelsen: do juspositivismo à democracia. Revista Direito GV, 16(2).

Camargo, M. M. L. (2003). Hermenêutica e argumentação: uma contribuição ao estudo do direito. (3a ed.), Renovar.

Diniz, M. H. (2010). Compêndio de introdução à ciência do direito: introdução à teria geral do direito, à filosofia do direito, à sociologia jurídica e à lógica jurídica. Norma jurídica e aplicação do direito. (21a ed.), Saraiva.

Dobrowolski, S. C. (1997). Justificação Jurídica e Sociedade Na Visão de Aulis Aarnio. Trabalho de Conclusão de Curso (Mestrado em Direito) Universidade Federal de Santa Catarina. https://core.ac.uk/reader/30386620.

Gadamer, H. G. (2003). Verdade e Método I: Traços de uma hermenêutica filosófica. Vozes.

Grau, E. (2002). Ensaio e Discurso sobre a Interpretação/Aplicação do Direito. Malheiros. 
Research, Society and Development, v. 11, n. 1, e4011124385, 2022

(CC BY 4.0) | ISSN 2525-3409 | DOI: http://dx.doi.org/10.33448/rsd-v11i1.24385

Kochem, R. (2021). Fundamentando decisões: uma doutrina lógico-argumentativa. Thoth.

Lima, T. A. de G. (2016). Iura Novit Curia no Processo Civil: Dos primórdios ao novo CPC. São Paulo: Revista de Processo, $251,127-158$.

Lopes, J. R. de L. (2016). Filosofia analítica e hermenêutica: preliminares a uma teoria do direito como prática. Brasília: Revista de Informação Legislativa, 53(212), 203-226.

Maranhão, C. de A. (2021). STJ entre cognitivismo e ceticismo interpretativo: obsolescência da Súmula 400 do STF, in: ALVIM, Teresa Arruda et al. (coords.). O CPC de 2015 visto pelo STJ [livro eletrônico]. São Paulo: Thompson Reuters Brasil.

Marinoni, L. G., Arenhart, S. C. \& Mitidiero, D. (2017). O Novo Processo Civil. (3a ed.), Revista dos Tribunais.

Medina, J. M. G. (2021). Código de processo civil comentado (3a ed.), Thomson Reuters Brasil.

Pereira, C. F. B. (2019). Fundamentação das decisões judiciais: o controle da interpretação dos fatos e do direito no processo civil. Thomson Reuters Brasil.

Streck, L. L. (2015). O novo Código de Processo Civil (CPC) e as inovações hermenêuticas: O fim do livre convencimento e a adoção do integracionismo dworkiniano. Brasília: Revista de Informação Legislativa, 52(206), 33-51, https://www12.senado.leg.br/ril/edicoes/52/206/ril_v52_n206_p33.pdf.

Taruffo, M. (2015). A motivação da sentença civil. Trad. Daniel Mitidiero, Rafael Abreu e Vitor de Paula Ramos. Marcial Pons.

Wróblewski, J. (1971). Legal decision and its justification. In HUBIEN, Hubert. Le Raisonnement Juridique: Actes du Congrès Mondial de Philosophie du Droit et de Philosophie Sociale. Bruxelles: Établissements Émile Bruylant, 409-419. 